\title{
TRAUMATIC SHOCK. VI. THE EFFECT OF HEMORRHAGIC SHOCK ON THE CONCENTRATION OF RENIN AND HYPERTENSINOGEN IN THE PLASMA IN UNANESTHETIZED DOGS ${ }^{1}$
}

\author{
BY LEWIS DEXTER, HOWARD A. FRANK, FLORENCE W. HAYNES, \\ AND MARK D. ALTSCHULE \\ (From the Medical Clinic of the Peter Bent Brigham Hospital, the Medical and Surgical \\ Research Laboratories, Beth Israel Hospital, and the Departments of \\ Medicine and Surgery, Harvard Medical School, Boston)
}

(Received for publication May 5, 1943)

Recent investigations have suggested that the renal enzyme, renin, plays a homeostatic rôle in the maintenance of normal blood pressure, since its concentration in the blood increases in a variety of hypotensive states, including shock due to hemorrhage ( 1 to 5 ). It seemed desirable to re-study this phenomenon in unanesthetized animals in order to avoid the complicating factor of anesthesia and to make additional studies on its mechanism and its action. Accordingly, observations have also been made in nephrectomized dogs, and in animals responding favorably or unfavorably to transfusion after hemorrhage. The blood of all animals studied has been assayed for hypertensinogen, since, on theoretical grounds, an increase in the concentration of renin in the blood might result after a time in a decrease in the concentration of hypertensinogen.

\section{METHODS}

Twenty normal and 4 nephrectomized street dogs, weighing from 6.3 to $16.0 \mathrm{kgm}$., were rendered hypotensive by hemorrhage. In all but 3 dogs, no anesthetic was used except morphine sulphate, $2 \mathrm{mgm}$. per $\mathrm{kgm}$., sometimes combined with atropine sulphate, 0.5 to $1.0 \mathrm{mgm}$., given intramuscularly; this served to keep the animals quiet but awake and responsive. In 4 dogs, nephrectomy was performed by the lumbar approach, under novocaine anesthesia, 10 to 70 minutes before hemorrhage was produced.

The animals were generally bled in amounts equal to 4 to $\mathbf{5}$ per cent of body weight, the volume withdrawn depending on the level of the blood pressure. It was attempted to maintain the blood pressure between 50 and 75 $\mathrm{mm}$. $\mathrm{Hg}$, during a period of several hours before death or

1 The work described in this paper was done under a contract, recommended by the Committee on Medical Research, between the Office of Scientific Research and Development and Harvard University. This investigation was aided by a grant from the John and Mary R. Markle Foundation. spontaneous recovery occurred. In 10 instances, the effect of transfusions was studied. Samples of blood were withdrawn at intervals from the femoral artery for the determination of renin, hypertensinogen, total protein, and hematocrit. The blood was chilled immediately and then

TABLE I

Effect of hemorrhage on blood pressure and concentration of renin and hypertensinogen in the plasma of unanesthetized dogs

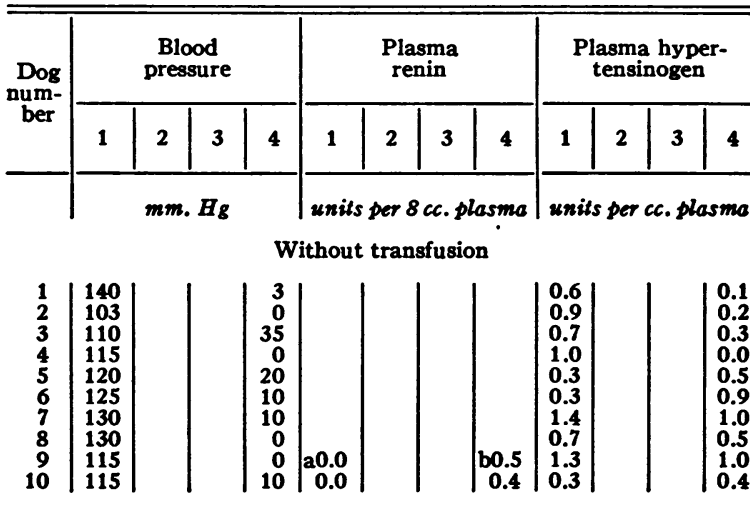

Transfusion without recovery

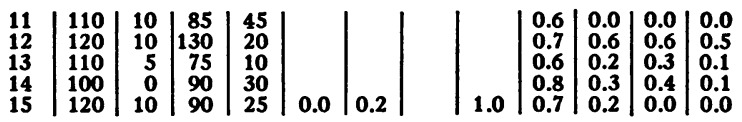

Transfusion with recovery

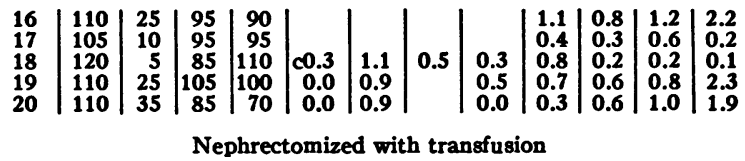

\begin{tabular}{l|l|l|l|l|l|l|l|l|l|l|l|l}
21 & 145 & 20 & 80 & 75 & & & \\
22 & 115 & 25 & 60 & 20 & 0.0 & $0.1 *$ & 0.0 & 2.6 & 1.6 & 2.3 & 2.0 \\
2.2 & & &
\end{tabular} Nephrectomized without trangfusion

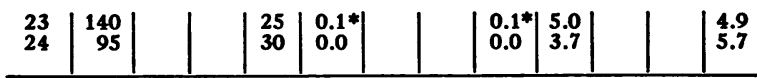

The figures at the top of each column indicate the following: (1) Before hemorrhage, (2) Before transfusion, (3) After transfusion, (4) Before death or at end of experiment.

a. Amount of renin in $3 \mathrm{cc}$. of plasma; b. in $4 \mathrm{cc}$. of plasma; c. in $6 \mathrm{cc}$. of plasma.

* Values of 0.1 or less are considered to be within the range of error and therefore negative. 


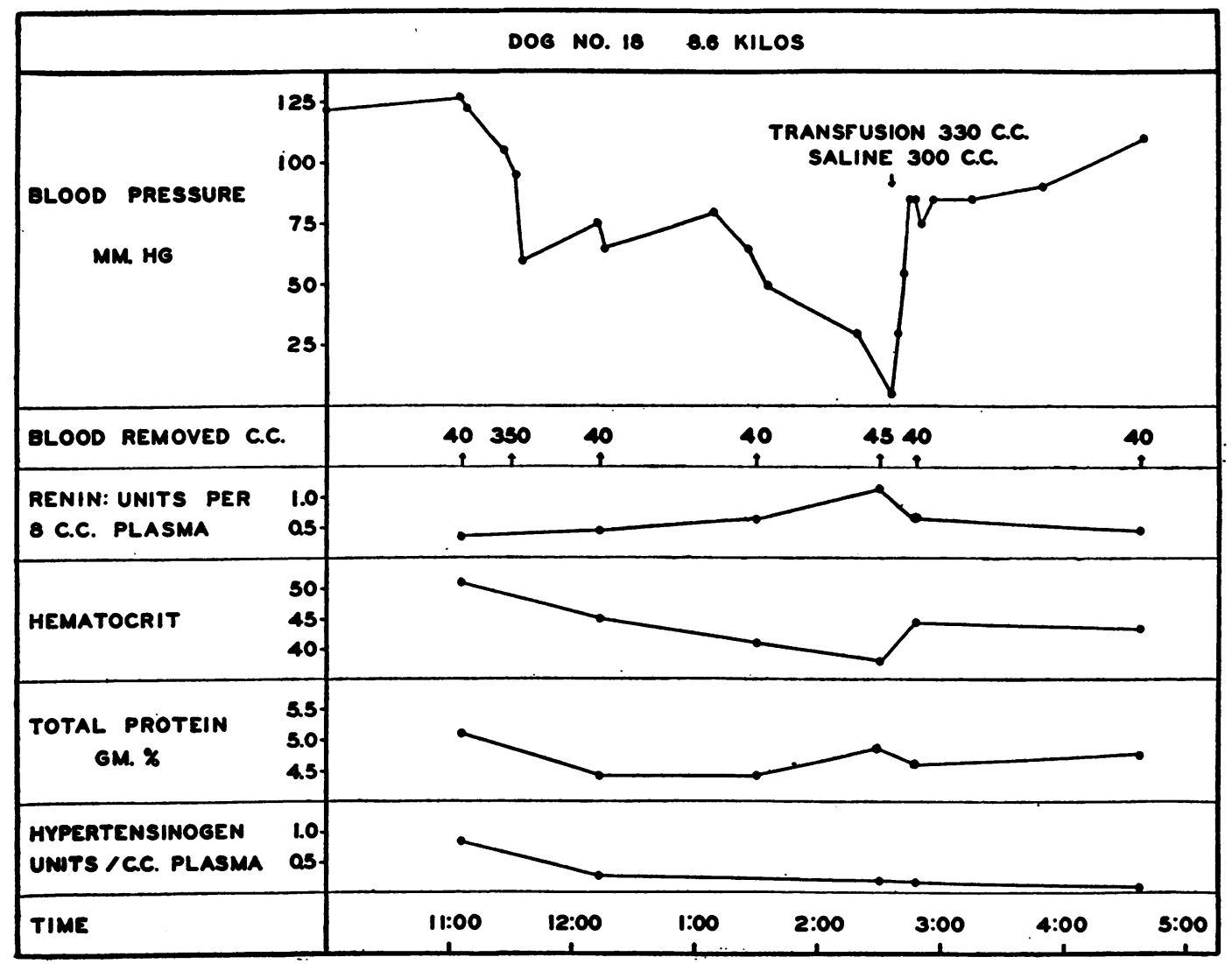

Fig. 1. Effect of Hemorrhage on Blood Pressure, Hematocrit, and Concentration of Renin, Total Protein, and Hypertensinogen of Plasma of Unanesthetized Dog

centrifuged. Heparin or sodium citrate was used as an anticoagulant. Blood pressure was determined in the femoral artery by an intra-arterial needle, connected with a mercury manometer. Total protein was measured by the falling drop method of Kagan (6).

Hog renin was prepared according to the method of Braun-Menendez and co-workers (7). The renin content of plasma was determined by a modification of the direct method of Leloir et al. (8). In early experiments, results were irregular after the injection of extracts of 8 to $15 \mathrm{cc}$. of plasma used for assay. In later experiments, the plasma was freed from many of its toxic substances, by dialysis for 24 hours against tap water at $5^{\circ} \mathrm{C}$., and then incubated in the usual manner. The results by this modification were satisfactory. The amount of plasma used in testing was usually $8 \mathrm{cc}$. The concentration of hypertensinogen in $4 \mathrm{cc}$. of plasma was determined as described by Leloir and co-workers (9). The concentrations of renin and hypertensinogen are expressed in cat units, one cat unit being equivalent to one-fourth of a dog unit, as defined by Leloir et al. (8).2 Assays were

2 We are indebted to Dr. Eduardo Braun-Menendez for sending us a sample of hypertensin of known potency from which we could standardize our unitage. carried out on cats, anesthetized with Dial-Urethane (Ciba) , $0.88 \mathrm{cc}$. per kgm., given intraperitoneally.

\section{RESULTS}

Renin. In the 6 dogs with intact kidneys, where the technique for the determination of renin was modified by dialysis, the renin concentration of plasma increased progressively as shock deepened (Table I, Figure 1). In 3 animals, surviving after transfusion (dogs $18,19,20$ ), the renin concentration decreased as blood pressure returned to normal. In $1 \mathrm{dog}$, dying despite transfusion ( $\operatorname{dog} 15)$, renin concentration of plasma continued to rise to a high level after the administration of blood.

Hypertensinogen. In 12 of 20 experiments, the hypertensinogen concentration of plasma fell

3 Dial-Urethane was supplied through the courtesy of Dr. Ernst Oppenheimer, Ciba Pharmaceutical Products. Incorporated, Summit, New Jersey. 
significantly in 1 to 3 hours (Table I, Figures 1, $2,3)$. In several instances of severe shock, no hypertensinogen could be detected in $4 \mathrm{cc}$. of plasma. In all cases, the decrease in hypertensinogen was out of proportion to the decrease in concentration of total plasma protein and to the fall in hematocrit. In 6 animals (dogs 9, 10, 12, $17,19,20)$, little or no change in the concentration of hypertensinogen was noted, despite prolonged hypotension. In 2 dogs (dogs 5,6 ), irregular changes in the concentration of hypertensinogen were observed.

Effect of nephrectomy. In 3 nephrectomized dogs in hemorrhagic shock, no renin appeared in the plasma. The hypertensinogen content of plasma was high after nephrectomy, remained unchanged in 2 dogs $(22,23)$, and actually increased considerably in 2 dogs in hemorrhagic shock (dogs 21, 24) (Table I, Figure 4).

Effect of transfusion. Ten dogs, after hemorrhage, received transfusions of approximately the same amount of blood that had been withdrawn to induce shock, i.e., 4 to 5 per cent of body weight. The blood contained nearly its normal complement of hypertensinogen. In 5 dogs which died, and in 2 which survived, no appreciable increase in the concentration of hypertensinogen could be detected immediately after transfusion (Table I, Figures 1, 3). In 3 animals which recovered, following transfusion (dogs 16, 19, 20), slight but definite increase in the concentration of hypertensinogen occurred.

\section{DISCUSSION}

Hamilton and Collins $(1,2)$ reported the appearance of pressor properties in the renal venous blood and, less markedly, in the renal arterial blood of dogs after hemorrhage, after injection of histamine, and after adrenalectomy. The pressor properties resembled those of either renin or hypertensin (angiotonin). Sapirstein, Ogden, and Southard (3) found that in dogs after hemorrhage, the circulating blood had a renin-like action on guinea pig ileum, but the renal origin of this property was not established. Following the intravenous injection of renin, a progressive rise in its concentration in the systemic blood of 2 dogs in shock, in contrast to its rapid disappearance

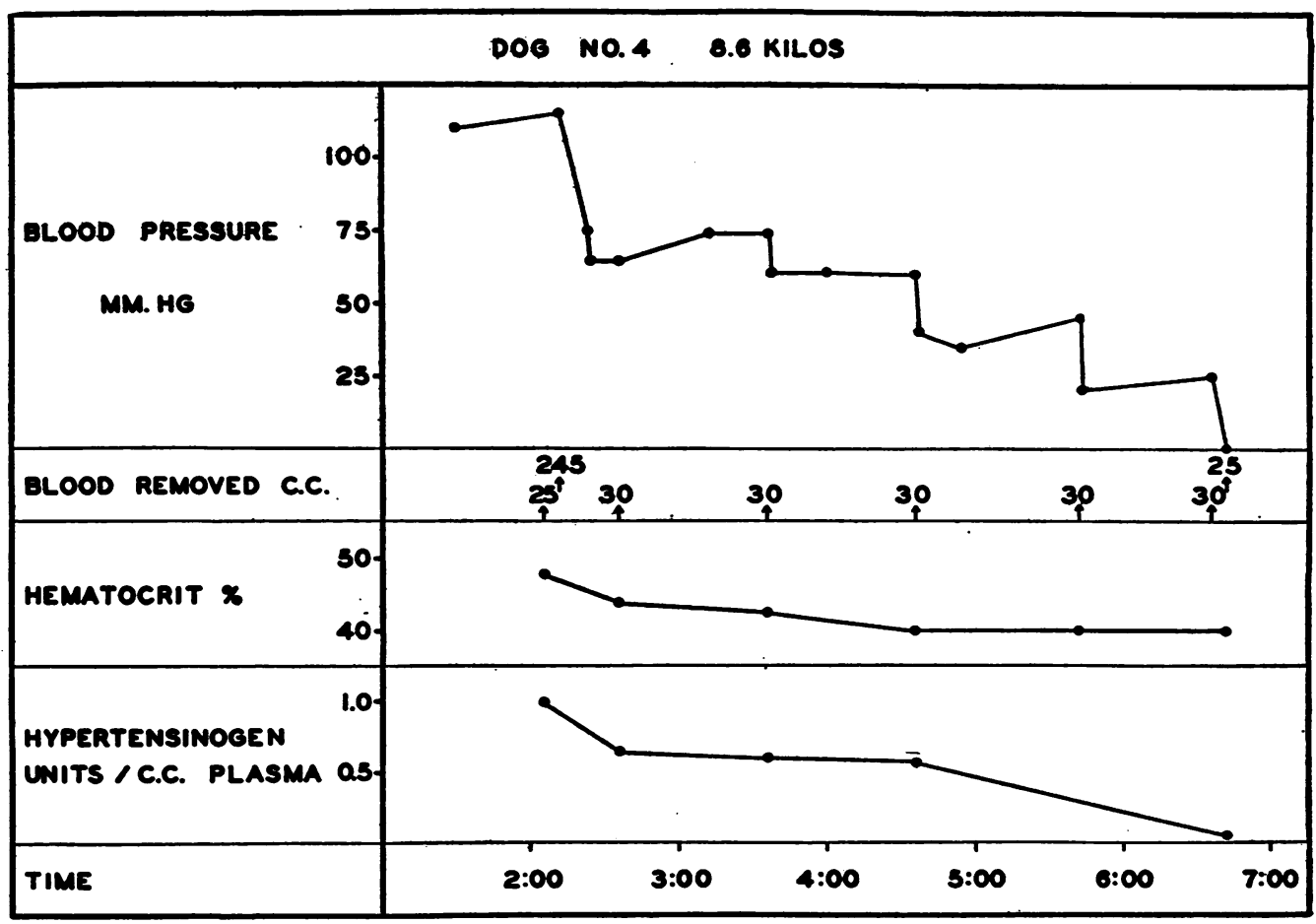

Fig. 2. Effect of Hemorrhage on Blood Pressure, Hematocrit, and Hypertensinogen Content of Plasma of Unanesthetized Dog 
from the blood of normal dogs, was observed by Houssay, Braun-Menendez, and Dexter (4). Huidobro and Braun-Menendez (5) extended this study and demonstrated the presence of renin in the systemic blood of anesthetized dogs after hypotension from hemorrhage, adrenalectomy with intestinal manipulation, or intravenous injection of amytal.

A diminution in the concentration of hypertensinogen in the blood of adrenalectomized animals was observed by Houssay and Dexter (10) and by Lewis and Goldblatt $(11,12)$. Although no renin was observed in the blood of these animals by the former investigators, it seemed possible that the decrease in the concentration of hypertensinogen in the blood of adrenalectomized animals might be attributable to its destruction by small amounts of renin, present in the blood as a result of hypotension, but not in sufficient amounts to be detected by the technique employed. Sapirstein, Southard, and Ogden (13) reported that the administration of renin-activator (hypertensinogen) to dogs in hemorrhagic shock resulted in an elevation of blood pressure which did not occur following the injection of a similar amount of gelatin solution. A diminution in the concentration of hypertensinogen in blood was noted by Leloir et al. (14) in an intact dog in shock following plasmapheresis. Collins and Hamilton (15) observed a decrease in its concentration in the plasma of dogs, after severe hemorrhage and after adrenalectomy, but this did not occur if the kidneys had been previously removed.

Our experiments confirm previous observations that in severe hypotension from hemorrhage, renin is liberated in easily detectable amounts into the systemic blood. This may possibly occur as a compensatory measure for maintaining the normal blood pressure. In many of the experiments, blood gas analyses were carried out and demonstrated the usual progressive decrease in the oxygen content of venous blood and markedly in-

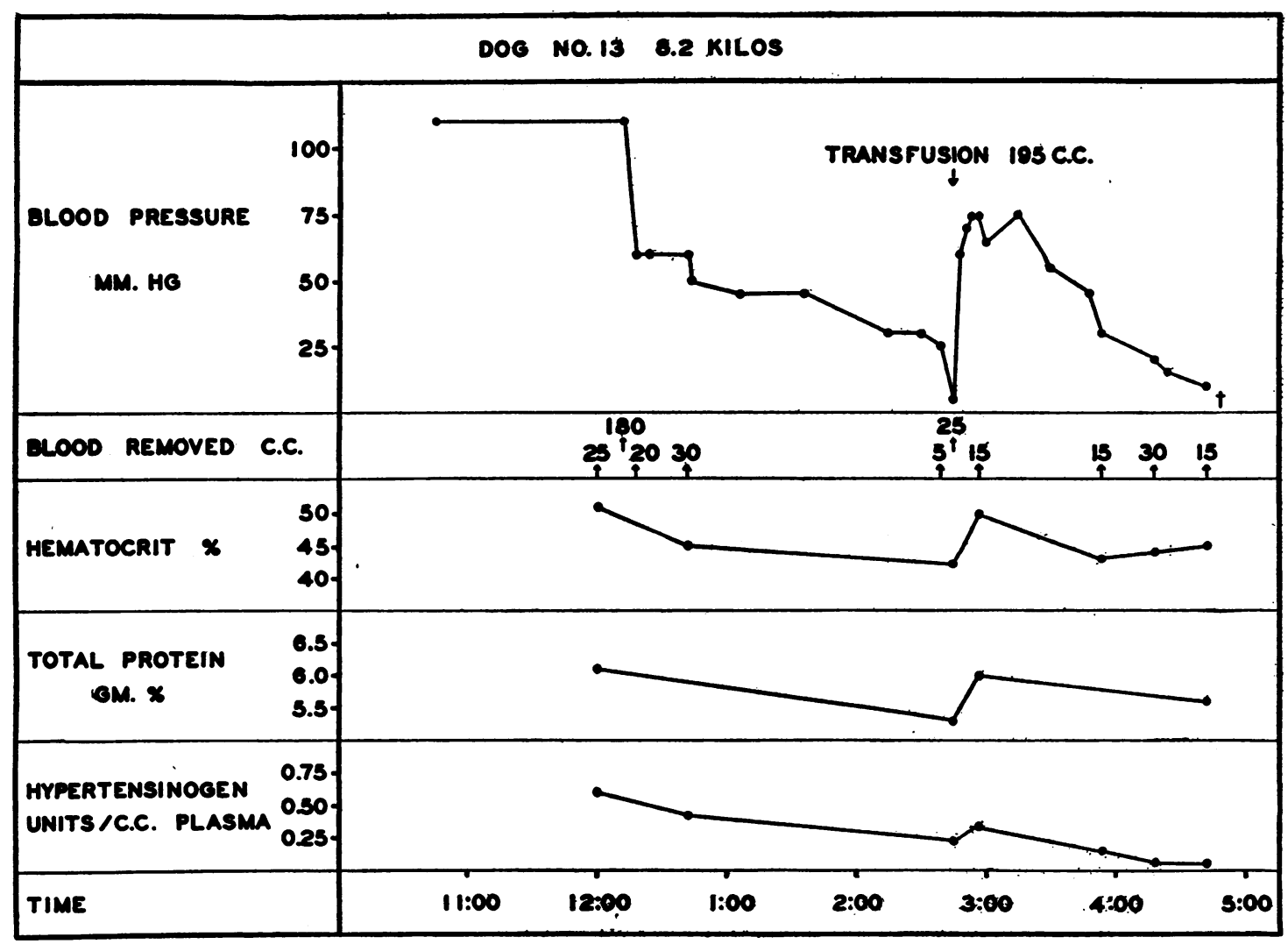

Fig. 3. Effect of Hemorrhage on Blood Pressure, Hematocrit, and Concentration of Total Protein and Hypertensinogen in Plasma of Unanesthetized Dog 


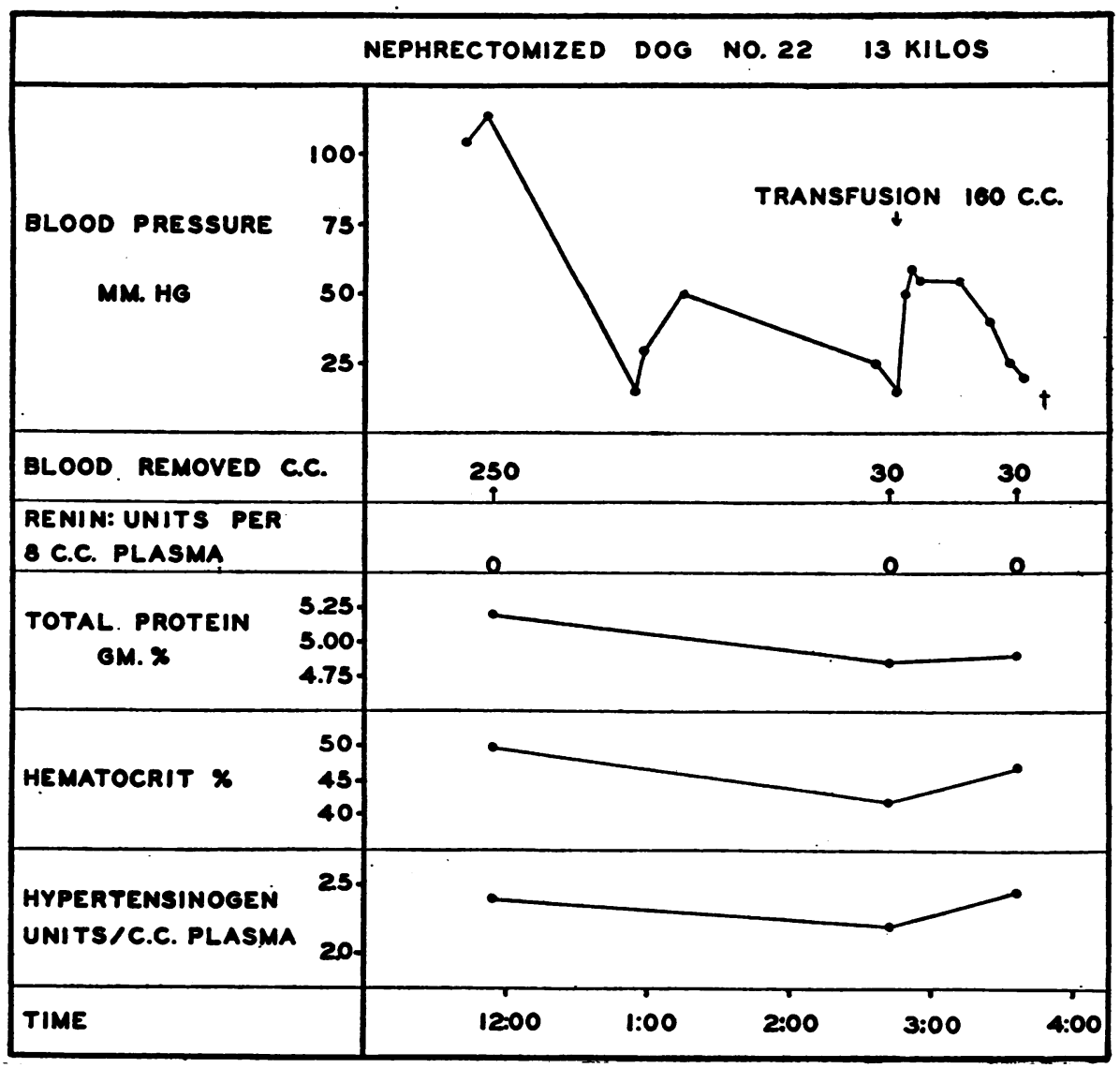

Fig. 4. Effect of Hemorrhage on Blood Pressure, Hematocrit, and Concentration of Renin, Total Protein, and Hypertensinogen in Plasma of Unanesthetized, Recently Nephrectomized Dog

creased arteriovenous oxygen difference during the period of hypotension. It might be postulated that the anoxemia, rather than the hypotension, gave rise to the liberation of renin. That this was not the case, however, was clearly indicated by the observations of Huidobro and Braun-Menendez (5) who found that renin was liberated as a result of lowering of blood pressure, but not as a result of anoxia from cyanide or from breathing an atmosphere containing as little as 6 per cent oxygen with an arterial oxygen saturation of 24 per cent.

After 1 to 3 hours of severe hypotension, the efficiency of the compensatory mechanism broke down, as was indicated by a progressive fall in the concentration of hypertensinogen of the plasma. In severe shock, the hypertensinogen content of plasma sometimes fell to a point where it was no longer detectable. The concentration of hypertensinogen in plasma obviously depends on its rate of conversion to hypertensin by renin and on its rate of formation. That renin was the sole factor concerned in its destruction was indicated by the fact that in shocked dogs, previously nephrectomized to prevent the formation of renin, the concentration of hypertensinogen either remained unchanged or actually increased. An elevated concentration of hypertensinogen in the plasma of nephrectomized dogs was reported by Leloir et al. (9), and was attributed to the absence of circulating renin. It is not known whether the synthesis of hypertensinogen is reduced in shock, but this may well be the case, since the synthesis of plasma protein has been shown to be decreased in shock (16). Transfusion of whole blood containing an ample titer of hypertensinogen, in amounts up to 6 per cent of the dogs' body weight, increased the concentration of hypertensinogen in plasma little, if any, if shock was severe. This 
failure to increase the hypertensinogen concentration of plasma by transfusion was presumably due to its almost immediate conversion to hypertensin by the great excess of circulating renin. While any colloidal solution will restore blood volume in shock due to hemorrhage, the use of those containing a high titer of hypertensinogen might conceivably be of value in supplying an adequate source of hypertensinogen for the synthesis of hypertensin.

\section{SUMMARY}

1. A study has been made of the renal humoral pressor mechanism, in unanesthetized dogs in shock, from the removal of 4 to 5 per cent of the body weight of blood.

2. It is confirmed that readily detectable amounts of renin appear in the circulating plasma.

3. The concentration of hypertensinogen in plasma decreases in severe hemorrhagic shock, sometimes to extremely low levels. Since in shocked dogs which had been nephrectomized, the concentration of hypertensinogen remained unchanged or increased, it is assumed that its diminution in shocked dogs with intact kidneys is due mainly or solely to the presence of excessive amounts of renin.

4. Transfusion of 4 to 5 per cent of body weight of whole blood, with nearly its normal titer of hypertensinogen, did not increase the concentration of hypertensinogen in plasma appreciably, presumably due to its almost immediate conversion to hypertensin by the large amount of circulating renin.

5. The renal humoral pressor mechanism is considered to represent a compensatory measure, on the part of the body, to maintain normal blood pressure in dogs rendered hypotensive by hemorrhage.

6. This mechanism functions inadequately, however, due to the inability of the organism to synthesize hypertensinogen as rapidly as it is converted to hypertensin by the large excess of circulating renin.

\section{BIBLIOGRAPHY}

1. Hamilton, A. S., and Collins, D. A., Role of the kidney in the maintenance of arterial blood pressure in hemorrhage. Am. J. M. Sc., 1941, 202, 914.
2. Hamilton, A. S., and Collins, D. A., The homeostatic role of a renal humoral mechanism in hemorrhage and shock. Am. J. Physiol., 1942, 136, 275.

3. Sapirstein, L. A., Ogden, E., and Southard, F. D., Jr., Renin-like substance in blood after hemorrhage. Proc. Soc. Exper. Biol. and Med., 1941, 48, 505.

4. Houssay, B. A., Braun-Menendez, E., and Dexter, L., The destruction and elimination of renin in the dog. Ann. Int. Med., 1942, 17, 461.

5. Huidobro, F., and Braun-Menendez, E., The secretion of renin by the intact kidney. Am. J. Physiol., 1942, 137, 47.

6. Kagan, B. M., Simple method for estimation of total protein content of plasma and serum; falling drop method. J. Clin. Invest., 1938, 17, 369.

7. Braun-Menendez, E., Fasciolo, J. C., Leloir, L. F., and Muñoz, J. M., The substance causing renal hypertension. J. Physiol., 1940, 98, 283.

8. Leloir, L. F., Muñoz, J. M., Braun-Menendez, E., and Fasciolo, J. C., Dosaje de la renina. Rev. Soc. argent. de biol., 1940, 16, 635.

9. Leloir, L. F., Muñoz, J. M., Braun-Menendez, E., and Fasciolo, J. C., La secreción de renina y la formación de hipertensina. Rev. Soc. argent. de biol., 1940, 16, 75.

10. Houssay, B. A., and Dexter, L., The sensitivity to hypertensin, adrenalin, and renin of unanesthetized normal, adrenalectomized, hypophysectomized and nephrectomized dogs. Ann. Int. Med., 1942, 17, 451.

11. Lewis, H. A., and Goldblatt, H., Studies on experimental hypertension. Bull. New York Acad. Med., 1942, 18, 459.

12. Goldblatt, H., Lewis, H. A., and Kahn, J. R., The Pathogenesis and Treatment of Hypertension: Experimental Observations. Nelson Loose Leaf Medicine, Survey of Current Literature, 1942.

13. Sapirstein, L. A., Southard, F. D., Jr., and Ogden, E., Restoration of blood pressure by renin activator after hemorrhage. Proc. Soc. Exper. Biol. and Med., 1942, 50, 320.

14. Leloir, L. F., Muñoz, J. M., Braun-Menendez, E., Taquini, A. C., and Fasciolo, J. C., La formación del hipertensinógeno. Rev. argent. de cardiol., 1942, 9, 269.

15. Collins, D. A., and Hamilton, A. S., Changes in angiotonin (hypertensin) and renin-activator (hypertensin precursor) in hemorrhage and shock. Federation Proc., 1943, $2,7$.

16. Ebert, R. V., Stead, E. A., Jr., Warren, J. V., and Watts, W. E., Plasma protein replacement after hemorrhage in dogs with and without shock. Am. J. Physiol., 1942, 136, 299. 